\title{
THE VALUE OF 3-DIMENSIONAL SPECKLE TRACKING ECHOCARDIOGRAPHY IN THE DIAGNOSIS AND EVALUATION OF CORONARY LESIONS IN STABLE ANGINA PECTORIS PATIENTS
}

\author{
By \\ Ahmed M. El-Benny, Yaser El-Sayed and Ali M. Al-Amin \\ Department of Cardiology, Faculty of Medicine, Al-Azhar University, Cairo, Egypt \\ E-mail: elbenyahmed@gmail.com
}

\begin{abstract}
Background: Echocardiography is the leading and feasible cardiac imaging in patients with cardiac disease. An early evaluation of patients with complex coronary lesions plays an important role in the prognosis and selection of treatment strategy.

Objectives: To compare and determine the value of 3D speckle tracking echocardiography (3D SE) at rest in diagnosis of coronary artery disease (CAD) in stable angina pectoris patients using SYNTAX score as a reference.

Patients and methods: A total of 90 patients with stable angina underwent invasive coronary angiography (CAG) enrolled into study from Islamic Cardiac Center at Al-Azhar University during the period from April 2017 to December 2019 and classified to case and control groups based on CAG results. Subjects underwent CAG and 3D-STE examination and SYNTAX score calculation, and then the patients were sub grouped according to SYNTAX score.
\end{abstract}

Results: There was a significant difference in strain measurement (Global longitudinal, circumferential and radial strain) between SYNTAX score sub-groups. The absolute value of different strain measurements decreased from low SYNTAX score to intermediate or high SYNTAX scores. For GLS was $-14.8 \pm 1.9 \%$,$11.08 \pm 1.7$ and $-7.4 \pm 1.2$, respectively, and for GAS was $-39.5 \pm 1.08,-25.95 \pm 7.09$ and $-14.6 \pm 1.86$, respectively, and for GCS was $-24.47 \pm 3.89,-14.96 \pm 2.41$ and $-8.73 \pm 2.53$, respectively, using ROC curve analysis the cut off value of GLS that differentiate between high SYNTAX score $(\geq 33)$ and non-high score $(\leq 32)$ was -7.7 and -17.1 for GAS and -12.5 for GCS. The cut off value of GLS that differentiate between low SYNTAX score $(\leq 22)$ and non-low score $(\geq 23)$ was-12.5.

Conclusion: Three-dimensional -STE is a noninvasive, reproducible, and efficient tool that has a potential clinical practice to evaluate the coronary lesion in chronic coronary syndrome patients. The absolute values of stain parameters were significantly associated with the complexity of coronary artery lesions.

Keywords: Three dimensional (3D), speckle tracking echocardiography (STE), stable angina, global longitudinal strain (GLS), SYNTAX score, coronary lesions.

\section{INTRODUCTION}

Echocardiography is the leading cardiac imaging technique in patients with suspected cardiac disease. However, conventional echocardiography at rest provides little information regarding the presence and extent of coronary artery disease $(\mathrm{CAD})$ in patients suffering from stable angina pectoris (SAP). An early evaluation of patients with severe and 
complex coronary lesions, such as 3vessel disease and/or left main lesion, plays an important role in the prognosis and selection of reasonable treatment strategy. In order to guide further treatment efficiently early before angiography, indicator to cost-effectively evaluate the severe and complex coronary lesions. The synergy between percutaneous coronary intervention with taxus and cardiac surgery (SYNTAX) score was established in the SYNTAX trial (Palmerini et al., 2011). It was reported as an angiographic tool grading the complexity of coronary artery disease (Hara et al., 2020). SYNTAX score is a comprehensive angiographic scoring tool based on lesions complexity in coronary vasculature (Neumann et al., 2019). The SYNTAX score could grade the degree of coronary artery stenosis and also assess calcification, tortuosity, bifurcation-, or trifurcation-type lesions in the coronary arteries. However, it is still an invasive method based on coronary angiography. The real-time 3-dimensional speckletracking echocardiography (3D-STE) can noninvasively and quantitatively assess the global and regional myocardial wall motion. The performance of this technology has been compared to the magnetic resonance imaging tagging technique (Liu et al., 2018). Studies have shown that strain and strain rate in the assessment of myocardial systolic dysfunction was superior to conventional wall motion analysis and left ventricular ejection fraction (LVEF) (Hayat et al., 2012). A previous study reported that 3dimensional global longitudinal strain (GPLS) derived from 3D-STE technology can detect subtle change of left ventricular (LV) longitudinal systolic function
(Ersboll et al., 2013). Thus, the strain or strain rate has the potential in early evaluation of the complex coronary artery disease.

The aim of the present study was to compare and determine the value of $3 \mathrm{D}$ speckle tracking echocardiography (3D $\mathrm{SE})$ at rest in diagnosis of coronary artery disease (CAD) in stable angina pectoris patients using SYNTAX score as a reference.

\section{PATIENTS AND METHODS}

This cross sectional study, included 90 patients with chronic coronary syndrome (stable angina) came to Islamic Cardiac Center at Al-Azhar University, for coronary angiography on clinical basis indications during the period from April 2017 to December 2019. Patients were classified into two groups according to the results of coronary angiography: Group (I): included 60 patients with different coronary lesions. Group (II): included 30 patients with normal coronary angiography. Group (I) was subsequently divided into three subgroups after coronary angiography according to the SYNTAX score: Group IA (low score = 0 -22), group IB (intermediate score $=22$ 32 ) and group IC (high score $\geq 33$ ).

Inclusion criteria: Stable angina pectoris was defined as chest pain or discomfort (angina) suspected to be due to myocardial ischemia. Symptoms of angina were considered stable if they have been occurring over several weeks without deterioration and typically induced by activity or stress.

Exclusion criteria: Acute coronary syndrome patients, prior myocardial infarction, prior coronary interventions, 
congestive heart failure, atrial fibrillation, significant valvular heart disease, cardiomyopathies, congenital heart disease, technically poor acoustic window for trans-thoracic echocardiography.

The clinical information of study population was recorded, such as age, gender, and cardiovascular risk factors including smoking, hypertension, and diabetes. The clinical data, including heart rate (HR), and body mass index (BMI), low-density lipoprotein cholesterol (LDL$\mathrm{C}, \mathrm{mg} / \mathrm{dL})$, triglycerides $(\mathrm{mg} / \mathrm{dL})$, and creatinine $(\mathrm{mg} / \mathrm{dL})$ were measured.

Echocardiographic data were acquired with an ultrasound Vivid E9 system (GE Vingmed Ultrasound AS, Horten, Norway), which was equipped with twodimensional 3.5-MHz transducer (M5SD), three -dimensional $3.5-\mathrm{MHz}$ transducer (4C-D), off-line speckletracking analysis software, and background processing work station (Echo PAC BT 11.1.0, GE Medical System, Horten, Norway).

All the patients were examined in the left lateral decubitus position. Echocardiographic images were acquired from the standard views (parasternal longaxis, parasternal short axis at level of the great vessels, apical four-chambers, apical five-chambers and apical two-chambers). Recordings and calculations of different cardiac chambers and ejection fractions were made according to the recommendations of the American Society of Echocardiography.

The 3-dimensional volumetric transducer was used to obtain a clear image of the LV endocardium with an apical 4-chamber view in the 4dimensional mode. The imaging allowed a sector with a depth of $30^{\circ}$ and a width of $100^{\circ}$ in real time. The larger pyramidal volume which was combined by small real-time subvolumes of 4 to 6 cardiac cycles were collected and stored. Threedimensional left ventricular end-diastolic volume, left ventricular end-systolic volume (LVESV), and GLS, GAS, GCS and GRS were obtained by the dedicated software. Patients with poor visualization (more than 2 segments) were excluded from further investigation.

All the coronary angiography (CAG) examinations were performed after the echocardiographic image acquisitions. The femoral artery was punctured by the method of Seldinger when the CAG was performed on all patients. Stenosis of more than $50 \%$ in the diameter of the left main coronary artery or stenosis of more than $75 \%$ in at least 1 major epicardial vessels or their main branches was considered clinically significant. The SYNTAX scores were calculated after the angiographic procedure using the online calculator (Genereux et al., 2011).

\section{Statistical analysis:}

All continuous variables were presented as mean \pm standard deviation. Categorical data were presented as frequencies and percentages $(\%)$. Comparisons of parametric values among groups (grouping by SYNTAX score: 022,22 , and above) [12, 13] were performed by Student's t-test and x 2 test, when appropriate. Receiver operator characteristic (ROC) curve analysis was performed to discover the optimal cutoff value of GLS, GAS, GCS and GRS for evaluating patients with intermediate or high SYNTAX scores. A 2-tailed $\mathrm{P}$ value $<0.05$ was considered significant. All Data 
were analyzed using Statistical Program for Social Science (SPSS) version 26.0.
SPSS software (IBMCompany, North Castle, NY).

\section{RESULTS}

In group I, the mean age was $57 \pm 4.7$ years, and $61.7 \%$ of the patients were males. About $65 \%$ of them had history of hypertension (HT), 36.7\% had diabetes mellitus (DM), and $53.3 \%$ of the patients were still smoking, while group II the mean age was $56 \pm 4.2$ years, and $61.7 \%$ of population were males. About $67.7 \%$ of them had history of hypertension (HTN), 70\% had diabetes mellitus (DM), and $53.3 \%$ of the patients were still smoking, men \pm SD of the studied parameters in each group and comparison between them showed no significant difference between two groups as regard age, HR, SYNTAX score and GLS, (p value less than 0.0001), and there were significant difference in between as regard LDL, TG, LVEF, SYNTAX score and GLS $p$ value was 0.0001 . As regard case group Mean GAS was $-29.8 \pm 10.02$, and GRS was 34.5 \pm 5.6 (Table 1).

Table (1): Comparison between case and control groups in demographics and laboratory data

\begin{tabular}{|c|c|c|c|c|c|c|}
\hline \multirow{2}{*}{\multicolumn{2}{|c|}{ Variables }} & \multicolumn{2}{|c|}{$\begin{array}{l}\text { Group I } \\
(\text { no. }=60)\end{array}$} & \multicolumn{2}{|c|}{$\begin{array}{c}\text { Group II } \\
(\text { no. }=\mathbf{3 0})\end{array}$} & \multirow[t]{2}{*}{$\mathbf{p}$} \\
\hline & & Mean & SD & Mean & SD & \\
\hline \multicolumn{2}{|c|}{ Age (years) } & 57 & 4.7 & 56 & 4.2 & $>0.05$ \\
\hline \multicolumn{2}{|c|}{ BMI } & 23.6 & 2.04 & 24.1 & 2.84 & $>0.05$ \\
\hline \multicolumn{2}{|c|}{$\begin{array}{l}\text { Heart rate } \\
\text { (Beat/min) }\end{array}$} & 76.2 & 5.1 & 78.2 & 6.9 & $>0.05$ \\
\hline \multicolumn{2}{|c|}{ LDL (mg/dl) } & 136.1 & 22.7 & 122.07 & 16.8 & 0.004 \\
\hline \multicolumn{2}{|c|}{ TG (mg/dl) } & 164.3 & 51.3 & 132.4 & 20.9 & 0.002 \\
\hline \multicolumn{2}{|c|}{ LV ESV (L/m) } & 55.7 & 16.03 & 45.5 & 5.002 & $<0.001$ \\
\hline \multicolumn{2}{|c|}{ LV EDV (L/m) } & 109.1 & 20.01 & 119.6 & 11.6 & $<0.008$ \\
\hline \multicolumn{2}{|c|}{ ED ES $(\mathrm{L} / \mathrm{m})$} & 53.3 & 7.8 & 74.1 & 8.01 & $<0.0001$ \\
\hline \multicolumn{2}{|c|}{ LV EF } & 0.49 & 0.07 & 0.6 & 0.02 & $<0.0001$ \\
\hline \multicolumn{2}{|c|}{ GLPS } & -12.06 & 3.07 & 15.5 & 2.01 & $<0.0001$ \\
\hline \multicolumn{2}{|c|}{ GAS } & -29.8 & 10.02 & -42.8 & 1.6 & $<0.0001$ \\
\hline \multicolumn{2}{|c|}{ GRS } & 34.5 & 5.6 & -29.6 & 11.8 & $<0.0001$ \\
\hline \multirow{2}{*}{\multicolumn{2}{|c|}{ GCS }} & -17.9 & 6.5 & 42.1 & 7.7 & $<0.0001$ \\
\hline & & No. & $\%$ & No. & $\%$ & \\
\hline \multirow{2}{*}{ Smoking } & yes & 28 & $46.7 \%$ & 19 & $63.3 \%$ & \multirow{2}{*}{$>0.05$} \\
\hline & no & 32 & $53.3 \%$ & 11 & $36.7 \%$ & \\
\hline \multirow{2}{*}{ HTN } & -ve & 21 & $35 \%$ & 10 & $33.3 \%$ & \multirow{2}{*}{$>0.05$} \\
\hline & +ve & 39 & $65 \%$ & 20 & $66.7 \%$ & \\
\hline \multirow[t]{2}{*}{ DM } & $\begin{array}{l}\text { Non- } \\
\text { DM }\end{array}$ & 38 & $63.3 \%$ & 9 & $30 \%$ & \multirow[t]{2}{*}{$<0.003$} \\
\hline & DM & 22 & $36.7 \%$ & 21 & $70 \%$ & \\
\hline
\end{tabular}


As regard SYNTAX groups there was a statistically difference between three SYNTAX groups (low, intermediate and high) as regard BMI, DM, HTN, smoking, LDL, TG and LVEF, number of coronary vessels affected, GLS,GAS, GCS and GRS with $\mathrm{P}$ value 0.0001 , while there were no statistically difference as regard age and HR Using ANOVA test for numerical variables and Chi-Square test for categorical variables. There were a significant difference in strain measurement (GLS,GAS,GCS and GRS) among SYNTAX score sub-groups ( $p$ value $=0.0001)$. The absolute value of GPLS decreased from low SYNTAX score to intermediate or high SYNTAX scores $(-14.8 \pm 1.9 \%,-11.08 \pm 1.7$ and -7.4 \pm 1.2 , respectively, $\mathrm{P}<0.0001$ ). Also, the value of Global area strain was decreased from low SYNTAX score to intermediate or high SYNTAX score $(-39.5 \pm 1.08$,$25.95 \pm 7.09$ and $-14.6 \pm 1.86$, respectively, $\mathrm{P}<0.0001)$. Global circumferential strain also decreased from low SYNTAX score to intermediate or high SYNTAX score ($24.47 \pm 3.89,-14.96 \pm 2.41$ and $-8.73 \pm 2.53$, respectively, $\mathrm{P}<0.0001$ ), (Table 2).

Table(2): Comparison between different SYNTAX score groups

\begin{tabular}{|c|c|c|c|c|}
\hline Groups & $\begin{array}{c}\text { Low score } \\
(\mathrm{n}=24)\end{array}$ & $\begin{array}{c}\text { Intermediate score } \\
(\mathrm{n}=28)\end{array}$ & $\begin{array}{c}\text { High score } \\
(\mathrm{n}=8)\end{array}$ & $\begin{array}{c}\mathrm{P} \\
\text { value }\end{array}$ \\
\hline Age (years) & $56.9 \pm 4.5$ & $58.2 \pm 5.03$ & $57.7 \pm 4.7$ & $>0.05$ \\
\hline BMI & $22.04 \pm 1.4$ & $24.17 \pm 1.5$ & $26.47 \pm 0.49$ & $<0.0001$ \\
\hline Male gender & $5(20.8 \%)$ & $25(89.3 \%)$ & $7(87.5 \%)$ & $<0.0001$ \\
\hline $\begin{array}{c}\text { Heart rate } \\
\text { (Beat/min) }\end{array}$ & $75.5 \pm 5.5$ & $76.8 \pm 4.7$ & $75.7 \pm 5.7$ & $>0.05$ \\
\hline Diabetes & $1(4.2 \%)$ & $14(50 \%)$ & $7(87.5 \%)$ & $<0.0001$ \\
\hline Hypertension & $7(29.2 \%)$ & $25(89.3 \%)$ & $7(87.5 \%)$ & $<0.0001$ \\
\hline Smoking & $1(4.2 \%)$ & $24(85.7 \%)$ & $7(87.5 \%)$ & $<0.0001$ \\
\hline LDL (mg/dl) & $115 \pm 13.06$ & $146 \pm 14.9$ & $161 \pm 18.9$ & $<0.0001$ \\
\hline TG (mg/dl) & $126 \pm 19.7$ & $176 \pm 42.5$ & $237.6 \pm 47.7$ & $<0.0001$ \\
\hline LV ESV & $43 \pm 12.5$ & $62.1 \pm 12.3$ & $71.6 \pm 8.8$ & $<0.0001$ \\
\hline LVEDV & $95.5 \pm 17.6$ & $116.6 \pm 16.2$ & $123.7 \pm 14.8$ & $<0.0001$ \\
\hline LVEF & $55.5 \pm 0.06 \%$ & $46.9 \pm 0.05$ & $42.04 \pm 0.032$ & $<0.0001$ \\
\hline No. of vessels & $0 \%$ & $10(35.7 \%)$ & $7(87.5 \%)$ & $<0.0001$ \\
\hline affected & $0.9 \%)$ & $27.8 \pm 3.19$ & $35.13 \pm 1.72$ & $<0.0001$ \\
\hline SYNTAX & $17.9 \pm 3.06$ & $-11.06 \pm 1.7$ & $-7.4 \pm 1.2$ & $<0.0001$ \\
\hline GLS & $-14.8 \pm 1.9$ & $-25.95 \pm 7.09$ & $-14.66 \pm 1.86$ & $<0.0001$ \\
\hline GAS & $-39.5 \pm 1.08$ & $-14.96 \pm 2.41$ & $-8.7 \pm 2.5$ & $<0.0001$ \\
\hline GCS & $-14.96 \pm 2.41$ & $33.93 \pm 1.97$ & $24.43 \pm 5.65$ & $<0.0001$ \\
\hline GRS & $38.52 \pm 3.83$ & & &
\end{tabular}

Receiver operator characteristic curves to predict cut off value of global longitudinal strain(GLS) that differentiate between patients with low SYNTAX score $(\leq 32)$ and high SYNTAX score ( $\geq 33)$, (Figure 1). 
Figure (1): Receiver operator characteristic curves to predict cut off value of global longitudinal strain(GLS)

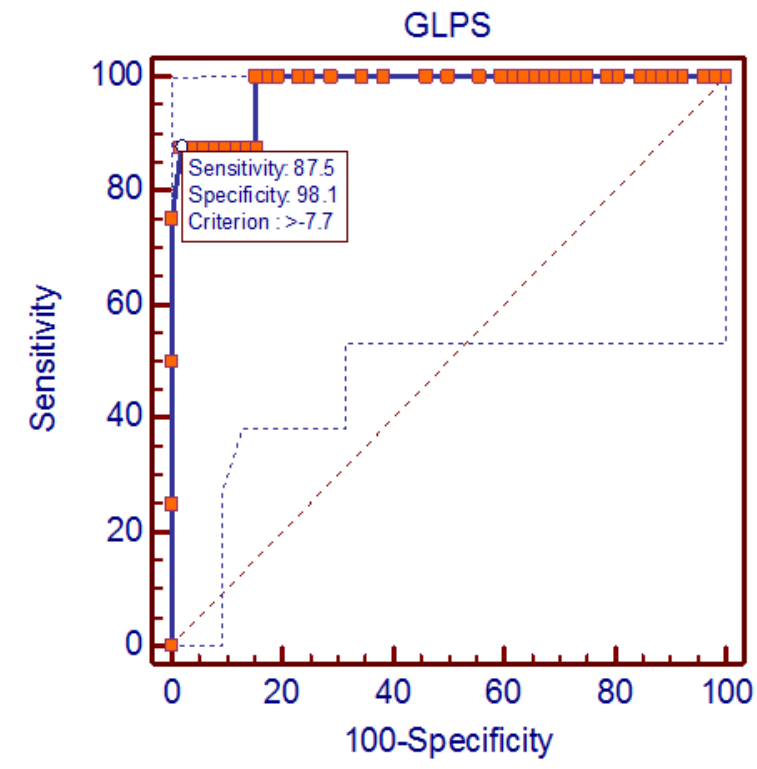

Receiver operator characteristic curves to predict cut off value of global area strain (GAS) that differentiate between patients with low SYNTAX score $(\leq 32)$ and high SYNTAX score $(\geq 33)$, (Figure 2).

Figure (2): Receiver operator characteristic curves to predict cut off value of global

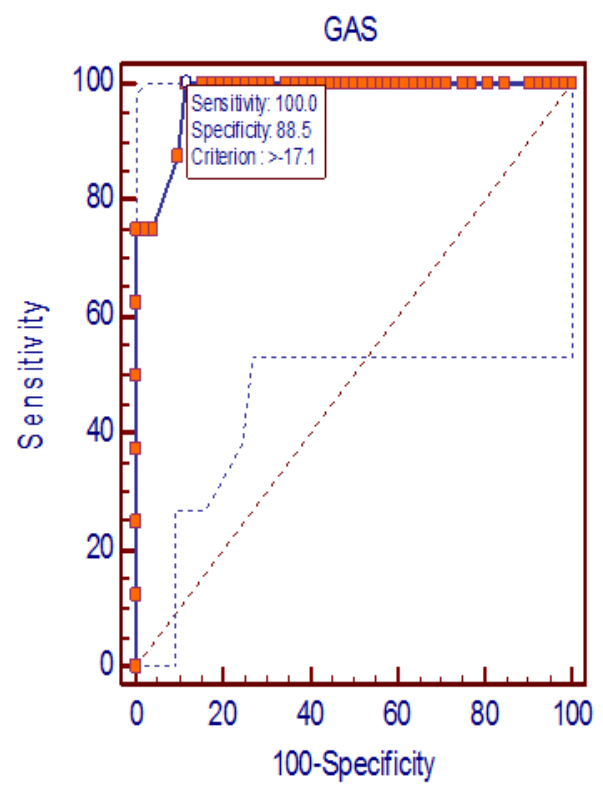

area strain (GAS) 


\section{DISCUSSION}

Our study showed that GLS, GCS, GRS and GAS levels correlated with SYNTAX score and can differentiate the degree of CAD complexity assessed by SYNTAX score. There were statistically significant differences between all strain parameters among the three SYNTAX score categories. The differentiation between SYNTAX score categories was crucial for decision of proper treatment strategy. Our study showed that the absolute value of GPLS decreased from low SYNTAX scores to intermediate or high SYNTAX scores other threedimensional speckle tracking parameter was measured in our study and results revealed that worsening of all measured stain parameter with increasing severity of CAD, i.e. increase SYNTAX score. Also, significant positive correlation was between measured strain parameter and SYNTAX score. The value of Global area strain decreased from low SYNTAX score to intermediate or high SYNTAX score Global circumferential strain also decreased from low SYNTAX score to intermediate or high SYNTAX score and global radial strain also decreased from low SYNTAX score to intermediate or high SYNTAX score. In our study, we found that GPLS levels had a strong correlation with the SYNTAX score, which used to calculate the severity of coronary lesions after coronary angiography. The optimal cut-off value of GPLS for identifying patients with severe and complex CAD as assessed by SYNTAX scores (more than 32) was $7.4 \%$, with area under the ROC curve (AUC) 0.980 (95\% confidence interval [CI], 0.905 to 0.999 ), with a sensitivity of $87.5 \%$ and a specificity of $98.1 \%$. While cutoff value of GPLS for identification of patients with SYNTAX score more than 22 was $-12.5 \%$ with area under the ROC curve (AUC) $0.901 \quad$ (95\% confidence interval [CI], 0.796 to 0.963), with a sensitivity of $97.2 \%$ and a specificity of $79.2 \%$.

These results coincided with results of (Mustafa et al, 2019) which showed that Mean of all strain parameters were significantly worse in patients with critical CAD group compared with noncritical CAD group, and also positive linear correlation was observed between Gensini score and all measured strain parameters. A GLS value of $>-10$ has $88.9 \%$ sensitivity and $92.9 \%$ specificity; A GAS value of $>-21$ has $97.2 \%$ sensitivity and $88.1 \%$ specificity to detect critical CAD. So, 3D-STE is a noninvasive and handy parameter to detect subclinical left ventricular dysfunction and global strain values were significantly correlated with CAD severity. GAS has the sensitivity of $97.2 \%$ and specificity of $88.1 \%$ to detect critical CAD. The discrepancy between our results and those of Mustafa et al., 2019 were due to exclusion of patients with abnormal LV function and patients with resting wall motion abnormalities. Also, they used a different score for definition of severe coronary artery disease.

There were a limited number of studies on the use of 3D-STE to assess the extent of coronary artery. However, there were several previous studies which used 2DSTE to evaluate the myocardial deformation were in agreement with our findings (Biering-Sorensen et al., 2014 and Alireza et al., 2015). 
Biering-Sorensen et al. (2014) concluded that in patients with suspected stable angina pectoris, global longitudinal peak systolic strain assessed at rest is an independent predictor of significant CAD and significantly improves the diagnostic performance of exercise test. Furthermore, 2-dimensional strain echocardiography seems capable of identifying high-risk patients as GLS decrease with more severe CAD lesions.

Resting GLS obtained by 2D-STE could identify patients with left main and/or3-vessel CAD without RWMA, According to ROC curve analysis, $-17.9 \%$ appears to be a helpful cutoff value for discriminating those with severe CAD (specificity $79 \%$ and sensitivity 79\%). There was a discrepancy in the value of GLPS by Edwards et al. (2019) results which showed that $-17.9 \%$ appears to be a helpful cutoff value for discriminating those with severe CAD (specificity 79\% and sensitivity 79\%). This was due to different definition of the complex coronary disease. Edwards et al. (2019) defined complex coronary lesion as patients with left main or 3-vessel disease and not detailed coronary assessment. In the present study, we used SYNTAX score to evaluate the coronary lesion, which has detailed coronary evaluation, including coronary calcification, tortuosity, bifurcation or trifurcation lesions. In addition, the study inclusion criteria were not the same. Their study included patients without regional wall motion abnormality, while our research included all patients with stable angina.

The results were nearly in agreement with Cai et al. (2016) for assessment of CAD severity in NSTE-ACS using GPLS assessed by 3D-STE at rest who showed that the values of GPLS significantly decreased from low SYNTAX scores to intermediate or high SYNTAX scores. The area under the receiver operator characteristic curve (AUC) for GPLS to evaluate patients with complex NSTEACS was 0.882 with an optimal cutoff value of $-11.76 \%$ (sensitivity $82.6 \%$ and specificity $83.3 \%$ ).

In our study, the regression analysis showed that diabetes mellitus and low GPLS level were great risk factors in the complexity of stable angina. While stable angina patients present with the above factors, they might have the high possibility of complex and severe coronary lesions and deserve to undergo an angiography, and to allow early timely treatment of CABG, or if PCI was planned to prepare equipment for complex PCI. Although 2D-STE was validated for the evaluation of myocardial deformation, 3D STE has been regarded as a more promising technique to accurately and reproducibly evaluate the segmental and global LV function (Biswas et al., 2013).

This was because 3D-STE did not affect by the foreshortened views, avoiding the out of plane motion weakness as the heart moves in and out of the incident imaging plane, making it difficult or impossible to track the same speckle during the heart cycle. Moreover, 3D-STE only needed 1 single apical 4chamber view to carry out all the analysis. Noteworthy, in our study, 3D-STE demonstrated the ability in detecting degree of severity of chronic coronary artery disease. This could be explained by the fact that longitudinally orientated myocardial helical fibers are located in the 
inner myocardium which is most susceptible to myocardial ischemia or transmural infarction (Biering-Sorensen et al., 2014).

Therefore, considering GPLS was superior to the LVEF, the ability of GPLS in the assessment of cardiac function has the potential to become clinical use (Krishnasamy et al., 2015).

In comparison to results of control group, global longitudinal strain (GLS) was $-15.5 \pm 2$ similar to results of multicenter study for detection of normal reference values of left ventricular strain using three-dimensional speckle tracking (Kleijn .et al., 2015).

\section{LIMITAIONS}

Small number of patients at a single center using single vendor machine and software. In spite of this limitation, GLS and other derived strain parameters from 3DSTE technique was found to be an independent predictor in the diagnosis of the complex coronary lesion. Bad resolution of $3 \mathrm{D}$ speckle tracking echocardiography was not suitable for all patients (obese, emphysematous chest, some females).

\section{CONCLUSION}

GLS and other strain parameters assessed by 3D-STE at rest are independent risk factors of the complex chronic coronary syndrome patients. The absolute value of GPLS and the values of other stain parameters are significantly associated with the complexity of coronary artery lesions in chronic coronary syndrome patients. The present study indicates that 3D-STE is a noninvasive, reproducible, and efficient tool that has a potential clinical practice to evaluate the coronary lesion in chronic coronary syndrome patients.

\section{ACKNOWLEDGMENTS}

Thanks to Taher Salman, Islamic Cardiac Center, Al-Azhar University, Cairo, Egypt, Yaser Abd El-Galeel, Faculty of Medicine, Al-Azhar University, Cairo, Egypt, and to Ahmed Saba, Faculty of Medicine, Al-Azhar University, Cairo, for their great efforts during this study.

\section{REFERENCES}

1. Alireza R, Maryam S, Yousef R. and Kasra D. (2015): Diagnostic accuracy of myocardial deformation indices for detecting high risk coronary artery disease inpatients without regional wall motion abnormality. Int $\mathrm{J}$ Clin Exp Med., 8:9412-20.

2. Biering-Sorensen $\mathrm{T}$, Hoffmann $\mathrm{S}$, Mogelvang R. Zeeberg Iversen A. and Galatius S. (2014): Myocardial strain analysis by 2-dimensional speckle tracking echocardiography improves diagnostics of coronary artery stenosis in stable angina pectoris. Circ Cardiovasc Imaging., 7:58-65.

3. Biswas M, Sudhakar S, Nanda NC. Pradhan $M$ and Roomi AU. (2013): Two- and threedimensional speckle tracking echocardiography: clinical applications and future directions. Echocardiography; 30:88105.

4. Cai, Z., Dai, J., Wu, D., Qiu, J., Ma, J., Li, G. and $\mathrm{Xu}, \mathrm{L}$. (2016): The value of 3dimensional longitudinal strain in the evaluation of complex coronary lesions in nonST-segment elevation acute coronary syndrome patient. Medicine (United States), 95(39):1-7.

5. Edwards, N.F., Scalia, G.M., Shiino, K., Sabapathy, S., Anderson, B., Chamberlain, R., Khandheria, B.K. and Chan, J. (2019): Global myocardial work is superior to global longitudinal strain to predict significant coronary artery disease in patients with normal left ventricular function and wall motion. Journal of the American Society of Echocardiography, 32(8): 947-957. 
6. Ersboll M, Valeur $\mathbf{N}$ and Mogensen UM. (2013): Prediction of all-cause mortality and heart failure admissions from global left ventricular longitudinal strain in patients with acute myocardial infarction and preserved left ventricular ejection fraction. J Am Coll Cardiol., 61:2365-73.

7. Genereux $P$, Palmerini $T$ and Caixeta $A$. (2011): SYNTAX score reproducibility and variability between interventional cardiologists, core laboratory technicians, and quantitative coronary measurements. Circ Cardiovasc Intervent., 4:553-61.

8. Hara, H., Kogame, N., Takahashi, K., Modolo, R., Chichareon, P., Tomaniak, M., Ono, M., Kawashima, H., Gao, C., Wang, R. and Valkov, V.D. (2020): Usefulness of the updated logistic clinical SYNTAX score after percutaneous coronary intervention in patients with prior coronary artery bypass graft surgery: Catheter Cardiovasc Interv, 2020;10.1002/ccd.28898.

9. Hayat D, Kloeckner M, Nahum J. and Roberto M. (2012): Comparison of real-time three dimensional speckle tracking to magnetic resonance imaging in patients with coronary heart disease. Am J Cardiol, 109:180-6.

10. Kleijn, S. A., Pandian, N. G., Thomas, J. D., De Isla P., Kamp, O., Zuber, M. and Zamorano J. (2015): Normal reference values of left ventricular strain using threedimensional speckle tracking echocardiography: Results from multicenter study. European Heart Journal Cardiovascular Imaging, 16(4): 410-416.

11. Krishnasamy R, Isbel NM and Hawley CM. (2015): Left ventricular global longitudinal strain (GLS) is a superior predictor of all-cause and cardiovascular mortality when compared to ejection fraction in advanced chronic kidney disease. PLoS One; 10:e127044.

12. Liu, J., Banchs, J., Mousavi, N., Plana, J.C., Scherrer-Crosbie, M., Thavendiranathan, $P$. and Barac, A. (2018): Contemporary role of echocardiography for clinical decision making in patients during and after cancer therapy. JACC: Cardiovascular Imaging, 11(8):11221131.

13. Mustafa D., Evrim S., Cahide and Soydas C. (2019): Speckle tracking echocardiography for assessment of coronary artery disease severity in stable angina pectoris: Echocardiography. 2019; 36(2):320-327.

14. Neumann, F.J., Sousa-Uva, M., Ahlsson, A., Alfonso, F., Banning, A.P., Benedetto, U., Byrne, R.A., Collet, J.P., Falk, V., Head, S.J. and Jüni, P., (2019): ESC/EACTS guidelines on yocardial revascularization. European Heart Journal, 40(2): 87-165.

15. Palmerini $T$, Genereux $P$ and Caixeta $A$. (2011): Prognostic values of the SYNTAX score in patients with acute coronary syndromes undergoing percutaneous coronary intervention: analysis from the ACUITY (Acute Catheterization and Urgent Intervention Triage strategy) trial. J Am Coll Cardiol., 57:2389-97.

16. Yamazaki $K$, Iijima $R$, and Nakamura $M$. (2016): High-sensitivity cardiac troponin $T$ level is associated with angiographic complexity of coronary artery disease: a crosssectional study. Heart Vessels; 31:890-6. 


\section{قيمة التتبع النقطي بواسطة الموجات فوق الصوتية للقبلب ثلاثية

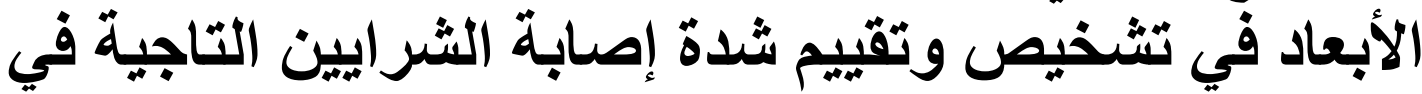 مرضى الأبحة الصدرية المستثرة} أحمد محمد محمد البني، ياسر السيا محمد حسن، علي محمد الأمين قسم القلب والأوعية الدموية، كلية الطب، جامعة الأزهر

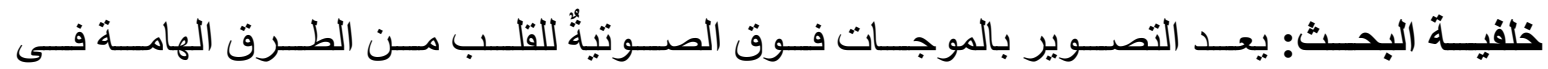

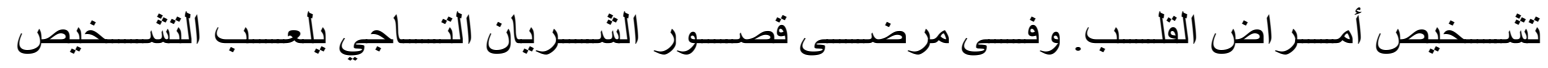
المبكر دور هام في التنبؤ واختيار خطة العلاج المناسب.

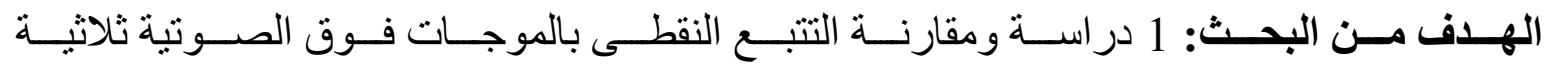

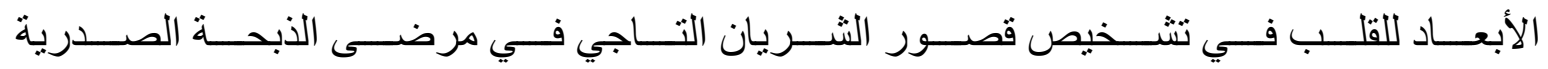

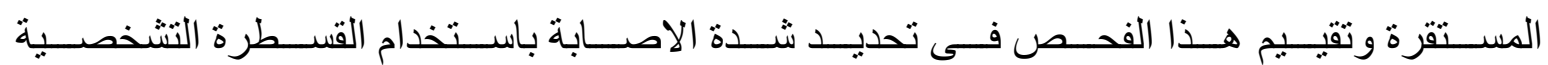
للشريان التاجي ومقياس سنتاكس كمرجع للمقارنة.

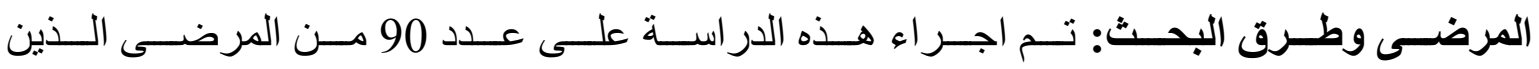

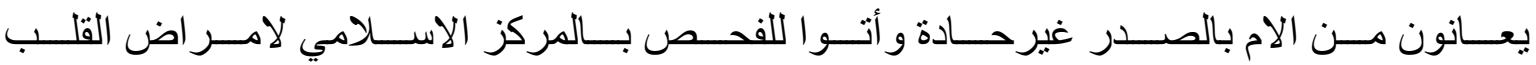

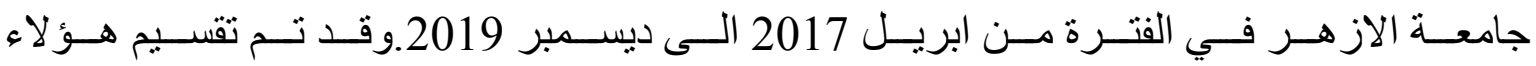
المرضى إلى مجمو عتين على حسب نتيجة القسطرة التشخيصية:

مجموعة أ: لا يوجد بها إصابة فى الثريان التاجى فى القسطرةالتشخيصية.

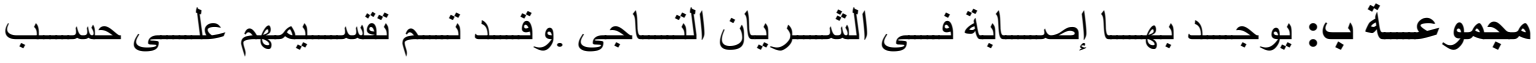

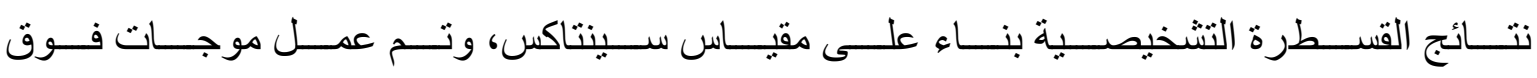

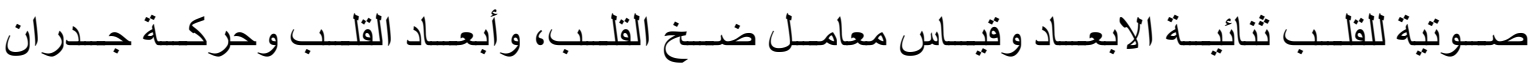

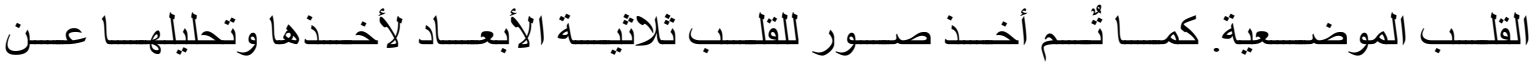

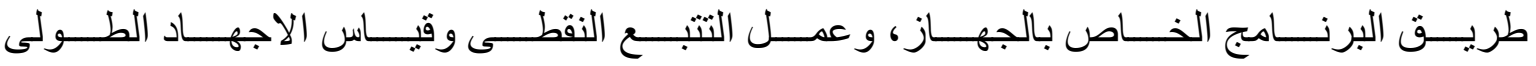

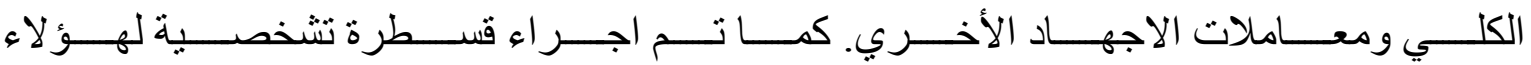

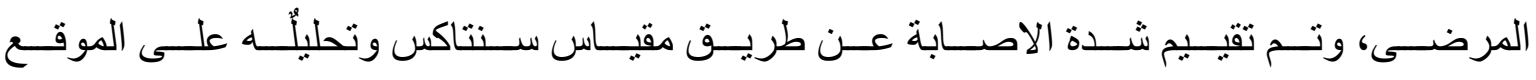

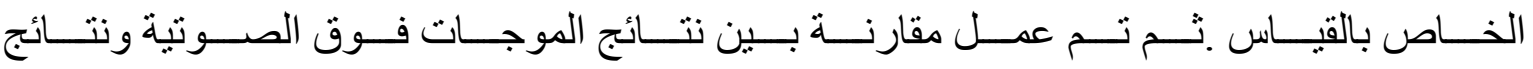




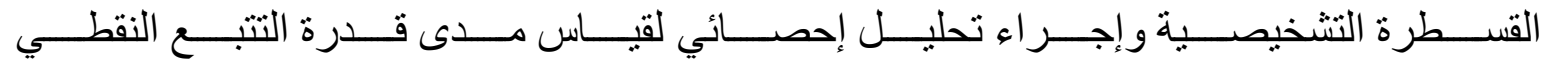

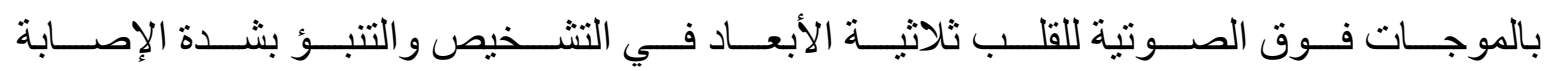
للشر ايين التاجية في مرضى الذبحة الصدرية المستقرة.

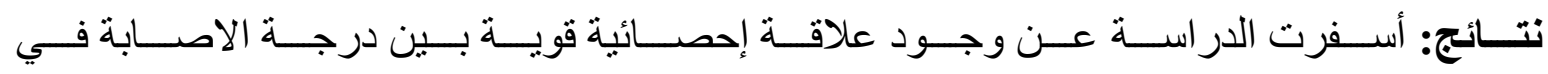

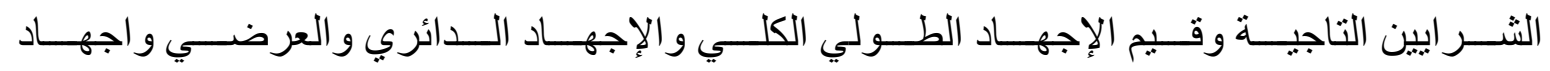

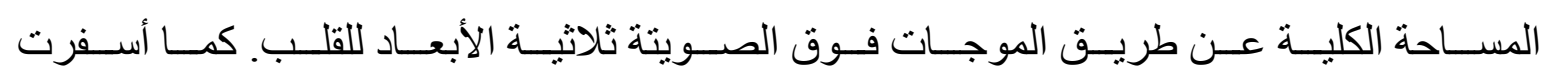

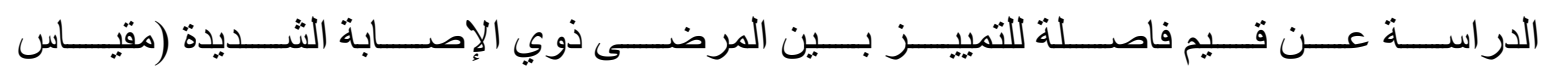

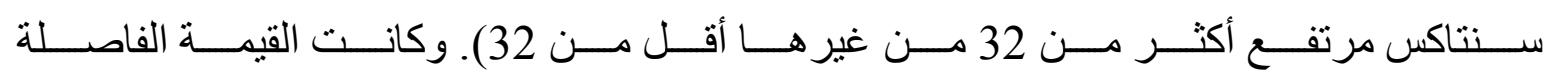

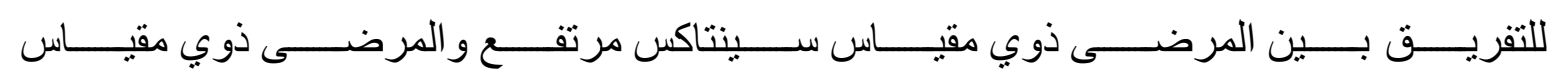

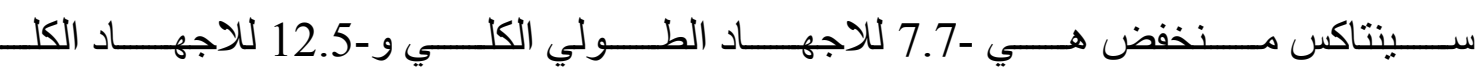

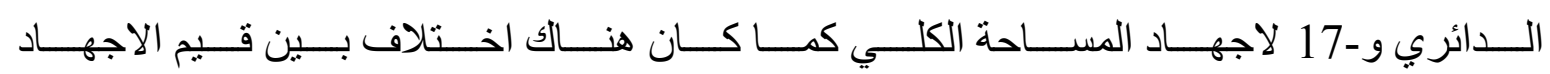
المختلفة بين مجمو عات مقياس سينتاكس.

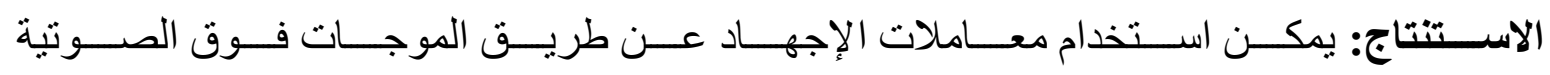
ثلاثية الأبعاد كمتنبيء بدرجة الإصابة بالثر ايين التاجية قبل اجر اءالقسطرة. 